\title{
Complete Spontaneous Regression of Pulmonary Metastatic Melanoma
}

\author{
TIMOTHY S. WANG, MD • LORI LOWE, MD \\ JOHN W. SMITH II, MD • ISAAC R. FRANCIS, MD \\ VERNON K. SONDAK, MD - LYNN DWORZANIAN, MS, RN, CS \\ STEVEN FINKELSTEIN • CRAIG L. SLINGLUFF, JR, MD \\ TIMOTHY M. JOHNSON, MD
}

BACKGROUND. Complete spontaneous regression of melanoma metastatic to the lungs is a rare event.

OBJECTIVE. To report a case of biopsy-proven melanoma metastatic to the lung with complete spontaneous regression.

METHODS. Multidisciplinary case report.

RESULTS. A 35-year-old white female was diagnosed with metastatic melanoma to the lung. A pleural biopsy confirmed the diagnosis. Partial spontaneous regression was noted by a staging computed tomography scan prior to enrollment in an investigational protocol. Complete spontaneous regression occurred over 5 months without any form of conventional or alternative therapy, and the patient remains disease-free 3 years after diagnosis. coNCLUSIONS. Our case represents the seventh case of complete spontaneous regression of melanoma metastatic to the lung, and the only case with histologic confirmation of both the primary and pulmonary metastatic lesions. The patient was pregnant twice between the time of her initial diagnosis of primary melanoma and pulmonary metastatic disease. (C) 1998 by the American Society for Dermatologic Surgery, Inc. Dermatol Surg 1998;24:915-919.

$\mathbf{S}$ pontaneous regression of cancer is defined as "the partial or complete disappearance of a malignant tumor in the absence of all treatment or in the presence of therapy which is considered inadequate to exert a significant influence on neoplastic disease."1 Spontaneous regression does not necessarily imply cure and need not result in complete disappearance of the tumor. Using these criteria, the spontaneous regression of cancer has been well described and is widely accepted as a rare phenomenon. ${ }^{1-19}$

Partial spontaneous regression of the primary lesion of melanoma is not uncommon, occuring in the range of

From the Departments of Dermatology (TSW, LL, SF, TMJ), Pathology (LL), Medicine (JWS, LD), Radiology (ISR), and Surgery (VKS), University of Michigan Medical Center, and Univeristy of Michigan Comprehensive Cancer Center, Ann Arbor, Michigan; and the Department of Surgery (CLS), Univeristy of Virginia, Charlottesville, Virginia.

Address correspondence and reprint requests to: Timothy $M$. Johnson, MD, University of Michigan/Dermatology, 1910 Taubman Center, Box 0314, Ann Arbor, MI 48109-0314.
$3-15 \%$ of cases. ${ }^{5,6,16,18}$ However, complete spontaneous regression of the primary lesion is rare and complete regression of metastatic lesions even rarer. Partial or complete spontaneous regression of metastatic melanoma most often occurs in cutaneous or nodal lesions.

Herein, we report a case of melanoma metastatic to the lungs with subsequent complete spontaneous regression of the metastatic lesions. This represents the seventh case reported in the English language literature (Medline) and the first with histologic confirmation of the pulmonary metastatic lesions.

\section{Case Report}

In August 1987, a 29-year-old gravid female noted a darkening lesion on the upper back. Biopsy revealed melanoma, type unclassified, $1.3 \mathrm{~mm}$ in Breslow depth extending to the deep margin. The patient underwent wide local excision with $4.0-5.0-\mathrm{cm}$ margins revealing scar and inflammation, and no residual melanoma. No evidence of regional or distant disease was noted based on a thorough history and physical examination. Postpartum, following delivery of a healthy baby in 1988, a chest $\mathrm{x}$-ray (CXR) revealed no abnormality, and abdominal ultrasound showed two hepatic hemangiomata that were stable from previous exams. The placenta was free of melanoma based on histologic and clinical evaluation.

In November 1992, the patient noted a new left axillary mass following the uncomplicated birth of her second child. Staging head and body computerized axial tomography (CT) scans revealed left axillary lymphadenopathy without evidence of additional disease. Open biopsy and subsequent left axillary lymph node dissection revealed one of $16 \mathrm{lymph}$ nodes positive for metastatic melanoma.

In August 1993, the patient noted a new soft tissue nodule in the left axillary dissection scar. Fine needle aspirate was positive for recurrent melanoma. Head and body CT scans demonstrated a tiny left upper lobe lung nodule that was too small to characterize and were 


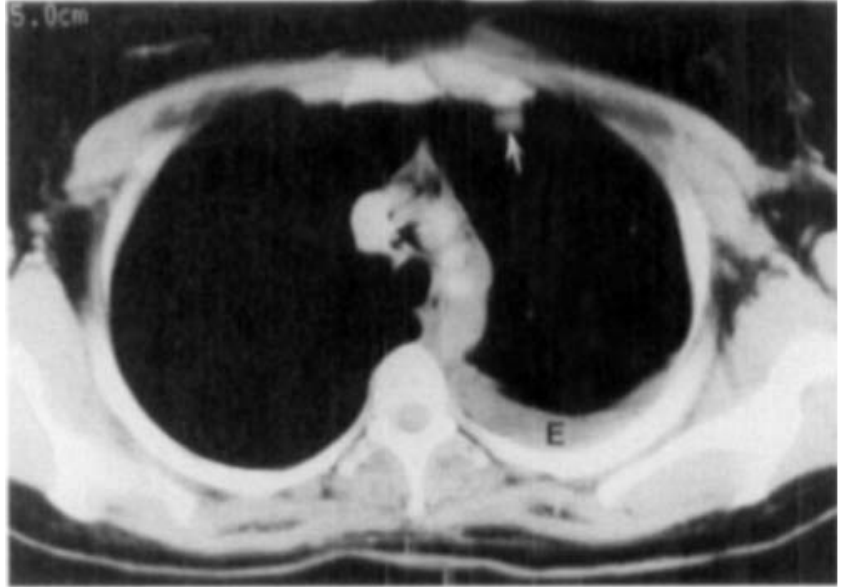

Figure 1. Contrast enhanced chest CT demonstrates a left upper lobe lung nodule (arrow), mediastinal lymph node enlargement, and a left pleural effusion (E).

otherwise unremarkable. Wide local excision of the soft tissue recurrent disease was performed.

In November 1993, the patient complained of increasing left-sided chest pain with pain on inspiration. Staging head and body CT scans demonstrated of a moderate sized left pleural effusion, a 1.5-cm left upper lobe lung nodule, left upper mediastinal, left internal mammary, and aorto-pulmonary window lymph node enlargement, and a $5 \times 6 \times 3-\mathrm{cm}$ mass contiguous with the gastroesophageal junction and the descending thoracic aorta (Figures 1 and 2). A pleural tap for cytology was negative for neoplasm with numerous reactive mesothelial cells. A CT-guided pleural biopsy was then performed revealing metastatic melanoma to the lungs (Figures 3 and 4). The pleural biopsy was complicated by a small pneumothorax that subsequently resolved.

In December 1993, the patient elected to enroll in an investigational protocol for stage IV melanoma. Prior to therapy, repeat head and body CT scans demonstrated

Figure 2. Contrast enhanced CT demonstrates a mass (M) contiguous with the gastroesophageal (GE) junction.

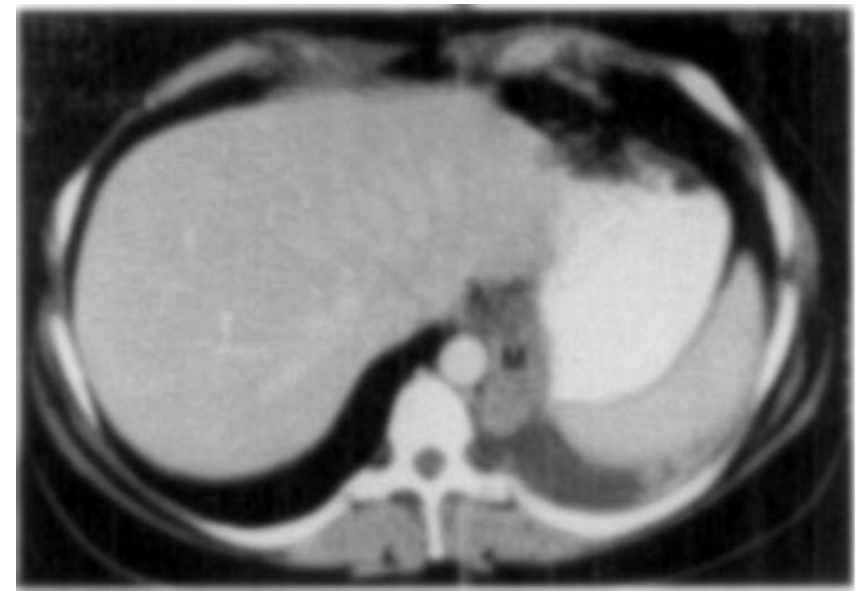

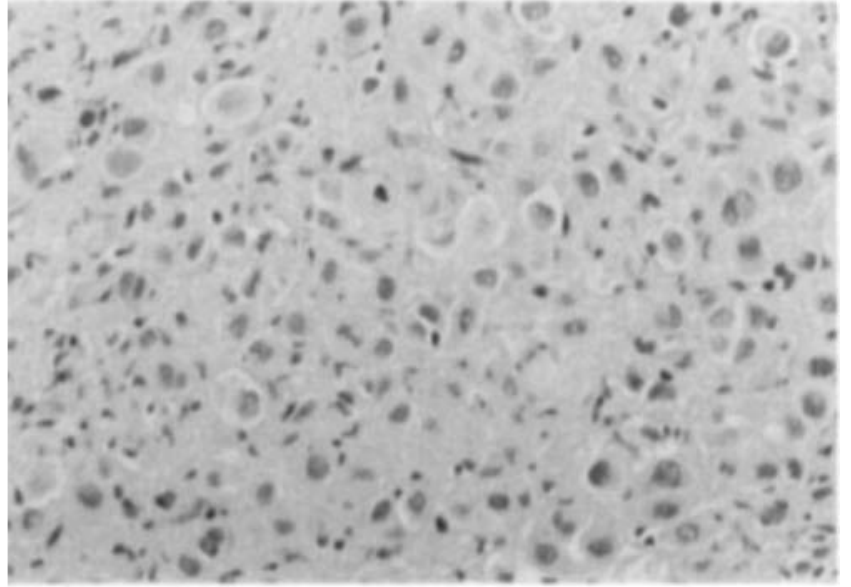

Figure 3. Pleural core biopsy demonstrates atypical epithelioid cells compatible with metastatic melanoma $(H \mathcal{E E}, \times 200)$.

a marked reduction in the size of the left pleural effusion and mediastinal lymph node enlargement with complete resolution of the left upper lobe lung nodule (Figure 5) with no other evidence of distant disease. The residual posterior mediastinal mass now measured $4 \times$ $4 \times 1.5 \mathrm{~cm}$ (Figure 6). Because of the observed improvement in the absence of treatment, the patient was not enrolled into the protocol. Follow-up CT scans in February 1994 showed continued improvement. A complete response with no evidence of disease was noted on chest CT scan in May 1994 (Figure 7). No further therapy was instituted and the patient remains free of disease 9 years after the initial diagnosis of melanoma and 4.5 years after the diagnosis of metastatic disease. The most recent CT scan in October 1996 and CXR in January 1997 demonstrated no evidence of recurrence. To date the patient has received no systemic therapy for her disease. Of note, specific detailed questioning revealed no change in diet, lifestyle, activity, or "alternative therapy."

Figure 4. S100 protein immunoperoxidase stain decorates the atypical malignant cells confirming a diagnosis of metastatic melanoma $(\times 400)$.

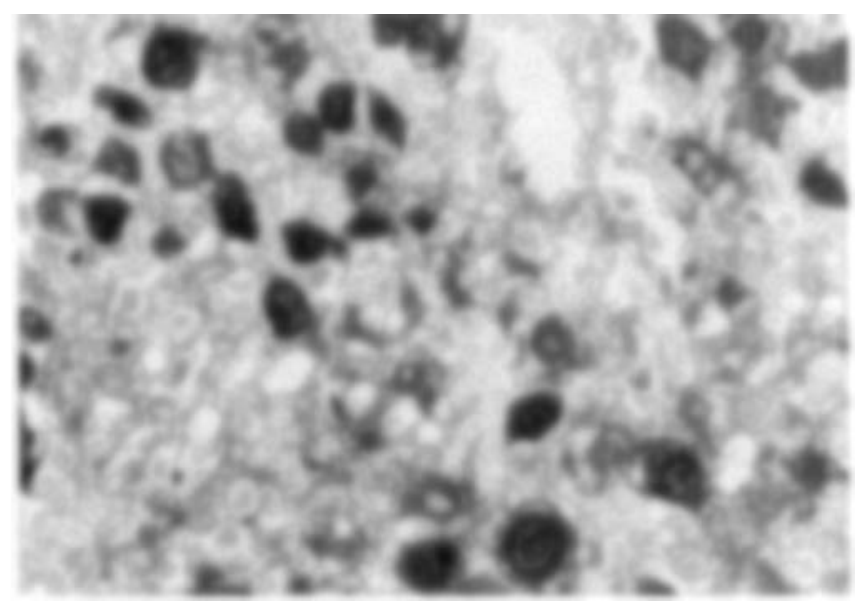




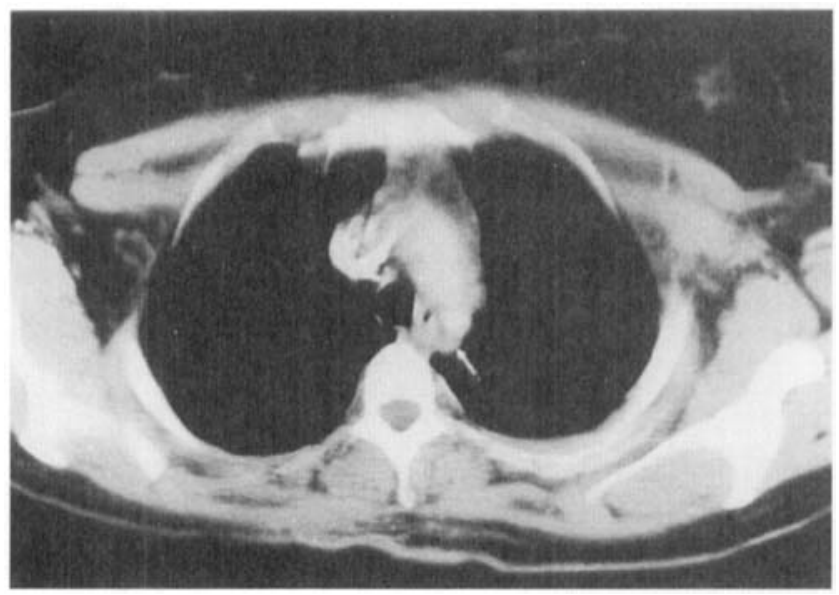

Figure 5. Spontaneous regression of left upper lobe lung nodule with minimal residual mediastinal lymph node enlargement (arrow) is noted on this follow up chest CT obtained 1 month later. Note also improvement in left pleural effusion.

\section{Discussion}

Spontaneous regression of metastatic melanoma is a rare event, reported as occurring in approximately $0.22-0.27 \%$ of cases. ${ }^{4,9,12,16,17}$ The complete spontaneous regression of metastatic melanoma was first reported in 1889 by Bennett. ${ }^{3}$ In 1979, Bodurtha reviewed 29 cases of spontaneous regression in metastatic melanoma. ${ }^{2,4}$ Of these, 26 had regression of cutaneous and/or lymphatic nodal metastases and five had regression of radiographically demonstrated pulmonary metastases. In 1986, Mikhail and Gorsulowsky reported one additional case of spontaneous regression of metastatic melanoma to the lungs. ${ }^{12}$ The present case represents the seventh report of complete spontaneous regression of melanoma with metastasis to the lungs and the first in the English language literature with histologic confirmation of pulmonary involvement (Medline). When evaluating cases of spontaneous regression in meta-

Figure 6. Mass ( $m$ ) contiguous with GE junction is also smaller.

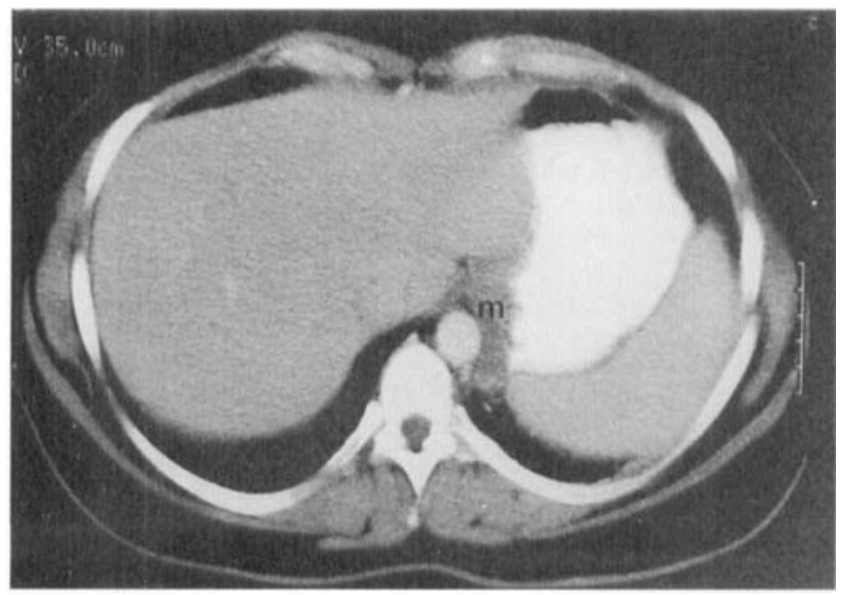

REGRESSION PULMONARY METASTATIC MELANOMA

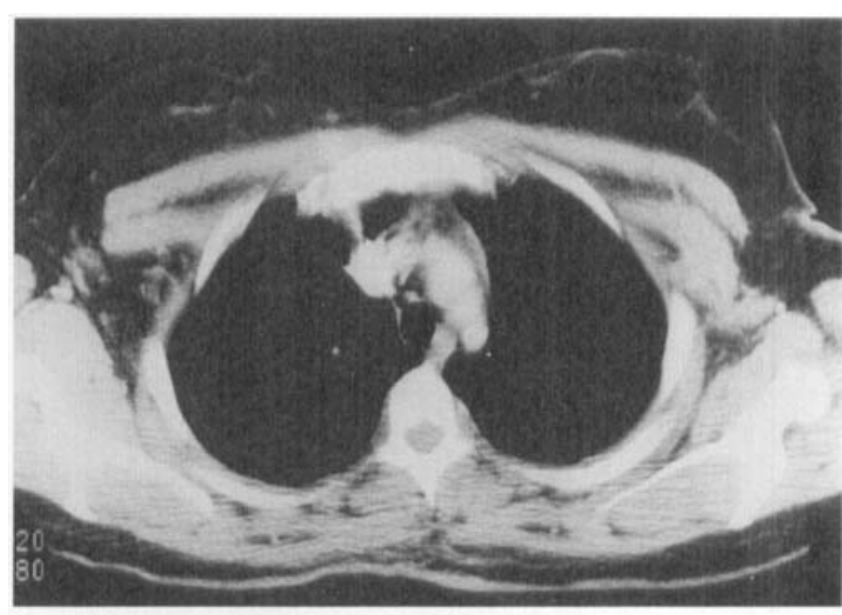

A

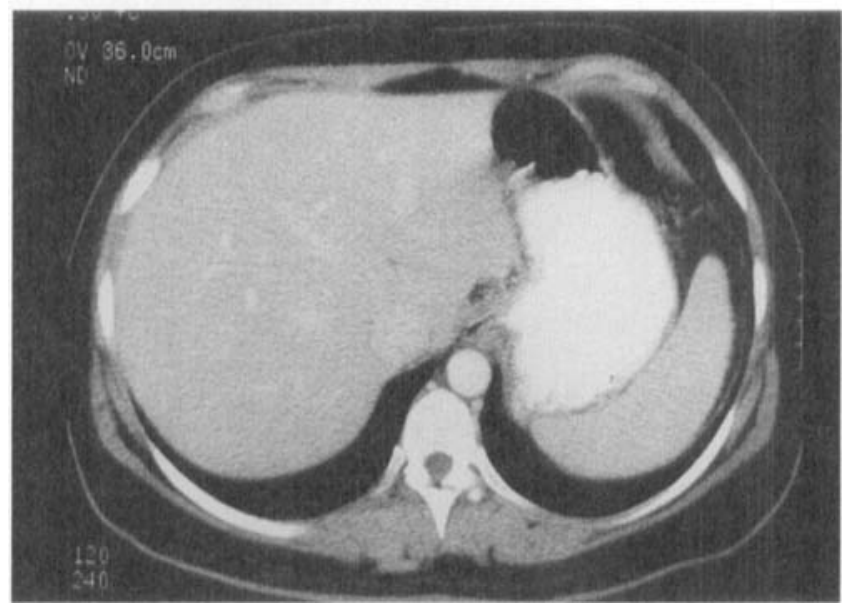

B

Figure 7. Complete resolution of left pleural effusion, mediastinal lymph node enlargement and mass contiguous with GE junction respectively is noted on this follow up CT obtained approximately 5 months after $\mathrm{CT}$ demonstrating metastatic disease.

static melanoma, histologic confirmation of the suspected lesion may be important due to the fact that open thoracotomy on patients with melanoma and radiographic lesions suspicious for pulmonary metastasis shows benign or unrelated disease in nearly one-third of cases. ${ }^{20}$

The single most important predictor of prognosis and risk of metastasis is the primary tumor thickness measured in millimeters (Breslow depth). ${ }^{21}$ While melanoma can metastasize to any organ, the most common sites of metastasis are the skin and subcutaneous tissue and lymph nodes. ${ }^{21}$ The most common visceral sites of metastasis are, in order of decreasing frequency, the lung, liver, brain, bone, and gastrointestinal tract. ${ }^{22-24}$ Given the relative frequency of pulmonary metastatic melanoma, the occurrence of spontaneous regression in these lesions based on reports in the literature must be rare indeed. Patients with pulmonary metastasis have 
an overall 5-year survival of approximately $4 \%$ and a median life expectancy of 6-7 months. ${ }^{25}$

A number of observations have stimulated interest in the role of pregnancy and melanoma. While controversial, most studies regarding prognosis of pregnancyassociated melanoma suggest a possible decreased disease-free interval but no effect on overall survival when controlling for tumor thickness and stage of disease. ${ }^{26-34} \mathrm{~A}$ waiting time of $0-5$ years to become pregnant after the diagnosis of melanoma is recommended depending on tumor thickness, stage of disease, patient age, and desire to get pregnant. Definitive answers to how pregnancy affects melanoma, if at all, remain unclear.

The mechanisms involved in the spontaneous regression of primary and metastatic melanoma are unknown but may be related to immunologic, endocrine, metabolic, hormonal, and nutritional factors. ${ }^{8-11,17}$ Alterations in immunity following infection, acute inflammation, or incomplete excision have been proposed as mediating factors. Postoperative infection did not occur in our patient, however, alterations in immunity secondary to inflammation following a pneumothorax may have influenced her complete spontaneous regression of biopsy-proven pulmonary metastatic melanoma.

Over the last 5 years, immunological studies of patients with melanoma have revealed that many have cytotoxic $T$ cell (CTL) responses to antigens that are present on melanoma cells. In patients treated with adoptive transfer of tumor-infiltrating lymphocytes, the presence of CTL reactive against gp100-derived epitopes has been correlated with favorable clinical response; these CTL may account for the mechanism of tumor regression in some patients who respond to interleukin-2 (IL-2)-based therapies. ${ }^{35}$ Some of these and other defined melanoma antigens are also present on normal cells of melanocytic origin, and patients who respond to IL-2 therapy often develop patchy vitiligo. Our patient did not develop vitiligo. We lacked a source of fresh autologous tumor after our patient went into remission and could not test her for the presence of CTL responses to autologous tumor. We obtained peripheral blood from the patient after her complete remission in hopes that we could determine the presence of CTL responses to defined HLA-A2-associated melanoma peptides such as those derived from MART-1/ Melan-A, tyrosinase, and gp $100 .^{36-49}$ Unfortunately, the patient's HLA type was HLA-A26, B18, B38, and to date, there are no defined epitopes for melanoma-reactive CTL associated with any of these MHC molecules. We plan to look for evidence of CTL responses in this patient as more melanoma epitopes become defined.

\section{References}

1. Everson TC, Cole WH. Anonymous Spontaneous Regression of Cancer. Philadelphia: WB Saunders Co., 1966:1-10, 164-220.

2. Boyd $W$. The spontaneous regression of cancer. In: Anonymous, ed. Springfield: Charles C. Thomas, 1966:15-24.

3. Bennett WH. Some peculiarities in the behavior of certain malig nant and innocent growths. Lancet 1899;1:3-7.

4. Bodurtha AJ. Spontaneous regression of malignant melanoma. In Clark WH, Goldman LI, Mastrangelo JM, editors. Human Malignant Melanoma. New York: Grune \& Stratton, 1979:227-41.

5. Spitler LE. Malignant melanoma. J Invest Dermatol 1976;67:43541.

6. McGovern VJ. Spontaneous regression of melanoma. Pathol 1975; 7:91-9.

7. Bulkley GB, Cohen MH, Banks PM, Char DH, Ketcham AS. Longterm spontaneous regression of malignant melanoma with visceral metastases. Cancer 1975;36:485-94.

8. Bodurtha AJ, Berkelhammer J, Kim YH, Laucius JF, Mastrangelo MJ. A clinical, histological and immunological study of a case of metastatic malignant melanoma undergoing spontaneous remission. Cancer 1976;37:735-42.

9. Nathanson L. Spontaneous regression of malignant melanoma: A review of the literature on incidence, clinical features, and possible: mechanisms. Nat Cancer Inst Monogr 1976;67-76.

10. Cole WH. Spontaneous regression of cancer: The metabolic triumph of the host? Ann NY Acad Sci 1974;230:111-41.

11. Rohdenburg GL. Fluctuations in the growth energy of malignant tumors in man, with special reference to spontaneous regression. J Cancer Res 1918;3:193-225.

12. Mikhail GR, Gorsulowsky DC. Spontaneous regression of metastatic malignant melanoma. J Dermatol Surg Oncol 1986;12:497500 .

13. Rampen FHJ, Meijer J. Metastatic melanoma of the brain after sontaneous regression of the primary. Acta Neurol Scand 1985; 72:222-3.

14. Pellegrini AE. Regressed primary malignant melanoma with regional metastasis. Arch Dermatol 1980;116:585-6.

15. Gromet MA, Epstein WL, Blois MS. The regressing thin malignant melanoma: a distinctive lesion with metastatic potential. Cancer 1978;42:2282-92.

16. Sroujieh AS. Spontaneous regression of intestinal malignant melanoma from an occult primary site. Cancer 1988;62:1247-50.

17. Hurwitz PJ. Spontaneous regression of metastatic melanoma Ann Plast Surg 1991;26:403-6.

18. Shai A, Avinoach I, Sagi A. Metastatic malignant melanoma with spontaneous and complete regression of the primary lesion. J Dermatol Surg Oncol 1994;20:342-5.

19. Avril MF, Charpentier P, Margulis A, Guillaume JC. Regression of primary melanoma with metastases. Cancer 1992;69:1377-81.

20. Pogrebniak HW, Stovroff M, Roth JA, Pass HI. Resection of pulmonary metastases from malignant melanoma: results of a 16year experience. Ann Thorac Surg 1988;46:20-3.

21. Johnson TM, Smith JW, Nelson BR, Chang A. Current therapy for cutaneous melanoma. J Am Acad Dermatol 1995;32:689-707.

22. Balch CM, Soong S, Murad TM, Smith JW, Maddox WA, Durant JR. A multifactorial analysis of melanoma. IV. Prognostic factors in 200 melanoma patients with distant metastases (stage III) J Clin Oncol 1983;1:126-34.

23. Amer $\mathrm{MH}, \mathrm{Al}$-Sarraf $\mathrm{M}$, Vaitkevicius VK. Clinical presentation, natural history and prognostic factors in advanced malignant melanoma. Surg Gynecol Obstet 1979;149:687-92.

24. Stehlin JS, Hills WJ, Rufino C. Disseminated melanoma. Biologic behavior and treatment. Arch Surg 1967;94:495-501.

25. Harpole DH, Johnson CM, Wolfe WG, George SL, Seigler HF. Analysis of 945 cases of pulmonary metastatic melanoma. J Thorac Cardiovasc Surg 1992;103:743-50. 
26. Slingluff CL Jr, Reintgen DS, Volmer RT, Seigler MF. Malignant melanoma arising during pregnancy: A study of 100 patients. Ann Surg 1990;211:552-9.

27. Shiu MH, Schottenfeld D, MacLean B, Fortner JG. Adverse effects of pregnancy on melanoma: a reappraisal. Cancer 1976;37:181-7.

28. Wong JH, Sterns EE, Kopland KH, Nizze JA, Morton DL. Prognostic significance of pregnancy in stage I melanoma. Arch Surg 1989;124:1227-30.

29. Elwood JM, Coldman AJ. Previous pregnancy and melanoma prognosis (letter). Lancet 1978;2:1000-1.

30. George PA, Fortner SG, Pack GT. Melanoma with pregnancy: a report of 115 cases. Cancer 1960;13:854-9.

31. Hersey P, Morgan G, Stone DE, McCarthy WH, Milton GW. Previous pregnancy as a protective factor against death from malignant melanoma. Lancet 1977;2:451-2.

32. Houghton AN, Flannery J, Viola MV. Malignant melanoma of the skin occurring during pregnancy. Cancer 1983;48:407-10.

33. Sutherland CM, Loutfi A, Mather FJ, Carter RD, Krementz ET. Effect of pregnancy on malignant melanoma. Surg Gynecol Obstet 1983;157:443-6.

34. Weiss NS, Flannery JT. The relationship of marital status to survival from melanoma. Cancer 1978;42:296-8.

35. Rosenberg SA. Development of cancer immunotherapies based on identification of the genes encoding cancer regression antigens. J Natl Cancer Inst 1996;88:1635-44.

36. Slingluff $C L$. Tumor antigens and tumor vaccines: peptides as immunogens. Sem Surg Oncol 1996;12:446-53.

37. Skipper JC, Hendrickson RC, Gulden PH, et al. An HLA-A2restricted tyrosinase antigen on melanoma cells results from posttranslational modification and suggests a novel pathway for processing of membrane proteins. J Exp Med 1996;183:527-34.

38. Wolfel T, Van Pel A, Brichard V, et al. Two tyrosinase nonapeptides recognized on HLA-A2 melanomas by autologous cytolytic T lymphocytes. Eur J Immunol 1994;24:759-64.

39. Kang $X$, Kawakami $Y$, el-Gamil $M$, et al. Identification of a tyrosinase epitope recognized by HLA-A24-restricted, tumor-infiltrating lymphocytes. J Immunol 1995;155:1343-8.
40. Brichard VG, Herman J, Van Pel A, et al. A tyrosinase nonapeptide presented by HLA-B44 is recognized on a human melanoma by autologous cytolytic T lymphocytes. Eur J Immunol 1996;26: 224-30.

41. Cox AL, Skipper J, Chen $Y$, et al. Identification of a peptide recognized by five melanoma specific human cytotoxic $\mathrm{T}$ cell lines. Science 1994;264:716-9.

42. Bakker $A B$, Schreurs $M W$, Tafazzul G, et al. Identification of a novel peptide derived from the melanocyte-specific gp 100 antigen as the dominant epitope recognized by an HLA-A2.1-restricted anti-melanoma CTL line. Int J Cancer 1995;62:97-102.

43. Kawakami $Y$, Eliyahu S, Jennings C, et al. Recognition of multiple epitopes in the human melanoma antigen gp100 by tumor-infiltrating $\mathrm{T}$ lymphocytes associated with in vivo tumor regression. J Immunol 1995;154:3961-8.

44. Bakker AB, Schreurs MW, de Boer AJ, et al. Melanocyte lineagespecific antigen gp100 is recognized by melanoma-derived tumor-infiltrating lymphocytes. J Exp Med 1994;179:1005-9.

45. Kawakami $\mathrm{Y}$, Eliyahu S, Delgado $\mathrm{CH}$, et al. Identification of a human melanoma antigen recognized by tumor-infiltrating lymphocytes associated with in vivo tumor rejection. Proc Natl Acad Sci USA 1994;91:6458-62.

46. Skipper JC, Kittlesen DJ, Hendrikson RC, et al. Shared epitopes for HLA-A3 restricted melanoma-reactive human CTL include a naturally processed epitope from Pmel-17/gp100. J Immunol 1996;157:5027-33.

47. Coulie PG, Brichard V, Van Pel A, et al. A new gene encoding for a differentiation antigen recognized by autologous cytolytic $T$ lymphocytes on HLA-A2 melanomas. J Exp Med 1994;180:35-42.

48. Kawakami $Y$, Eliyahu S, Sakaguchi $K$, et al. Identification of the immunodominant peptides of the MART-1 human melanoma antigen recognized by the majority of HLA-A2-restricted tumor infiltrating lymphocytes. J Exp Med 1994;180:347-52.

49. Castelli C, Storkus WJ, Maeurer MJ, et al. Mass spectrometric identification of a naturally processed melanoma peptide recognized by CD8 + cytotoxic T lymphocytes. J Exp Med 1995;181: 363-8. 